\title{
The Evil Within: The AMORAL Model of Dark Creativity
}

\author{
Hansika Kapoor ${ }^{1,2}$ and James C. Kaufman ${ }^{2}$ \\ ${ }^{1}$ Department of Psychology, Monk Prayogshala, Mumbai, India \\ ${ }^{2}$ Neag School of Education, University of Connecticut, USA
}

\begin{abstract}
Author Note
Hansika Kapoor (iD https://orcid.org/0000-0002-0805-7752

James C. Kaufman (iD https://orcid.org/0000-0003-0595-2820
\end{abstract}

The authors declare that there are no potential conflicts of interest with respect to the research, authorship, and/or publication of this article.

Correspondence concerning this article should be addressed to Hansika Kapoor, Research Author, Department of Psychology, Monk Prayogshala (Sec 8), 4114, Oberoi Garden Estates, Near Chandivali Studios, Powai, Mumbai-400072, India.

Email: hk@monkprayogshala.in

This is a preprint of the article published in Theory and Psychology: https://journals.sagepub.com/doi/10.1177/09593543221074326 


\begin{abstract}
The dark side of creativity entails using original thought to meet a selfish, negative, or evil goal, with or without the deliberate intent to harm others. Recent empirical advances have studied the behavioral correlates of such creativity, including associations with aggression, deception, and subclinical psychopathy. The time, therefore, seems apt to propose a theoretical framework for dark creativity's development and manifestation. This paper outlines the AMORAL model of dark creativity, which traces a creative action from its Antecedents to Mechanisms and Operants to its Realization, and to the subsequent Aftereffects and Legacy of the act. We use both real-life and simulated examples to illustrate the application of the theory across multiple domains, from law enforcement to interpersonal relationships. Our goal is to help guide future scholarship and measurement.
\end{abstract}

Keywords: creativity; deception; malevolent creativity; theoretical model; valence 


\section{The Evil Within: The AMORAL Model of Dark Creativity}

Creativity is typically defined as being both original and task-appropriate (e.g., Barron, 1955; Plucker et al., 2004). Originality refers to whether the creative action is novel and infrequent, which may include being surprising or non-obvious (Simonton, 2016). Taskappropriateness suggests that the idea fulfils some purpose and has value in a given context. Such actions also imply subjective social consensus (Stein, 1953).

Beyond definitions, there are numerous theories about creativity, its motivators (Amabile \& Pratt, 2016), determinants (Sternberg \& Lubart, 1992), and broader contexts (Sawyer, 2012). Stage-based models outline how the creative process unfolds through nonlinear phases (Wallas, 1926) as well as the cognitive processes underlying creative thought, such as problem identification (Mumford et al., 1991). Rhodes' (1961) 4Ps (person, press, product, process), Glaveanu's (2013) 5As (actor, action, artifact, audience, affordance), and more recently Sternberg's (2021) 8Ps (purpose, press, person, problem, process, product, propulsion, public) are alliterative theoretical frameworks to understand the emergence and sustenance of creativity. For all their differences, these theories largely share the assumption that creativity is a positive force that is beneficial for the individual and society. Therefore, most theories implicitly emphasize positive or benevolent creativity_original and useful ways to meet desirable and constructive goals (James et al., 1999).

On the other end of the valence spectrum lie the dark (McLaren, 1993), negative (James et al., 1999), and malevolent forms of creativity (Cropley et al., 2008). A growing body of empirical scholarship has explored the nuances of these concepts and how they differ from benevolent conceptions (Cropley et al., 2010; Cropley \& Cropley, 2019). McLaren (1993) focused on the dark side in artistic, technological, and scientific creativity and elaborated the need to study outcomes in relation to their societal and moral implications. 
Later, James et al. (1999) conceptualized negative creativity as using original means to meet socially undesirable goals. The doer does not have the deliberate intent to harm others, though such damage may be a byproduct of their actions. Thereafter, Cropley et al. (2008) described malevolent creativity as using novel ways to meet destructive goals to deliberately cause harm. The solutions used by criminals can also be original and task-appropriate to serve antisocial ends. The novelty of a creative solution decays over time, with exposure leading to a reduction in surprise, thus reducing its effectiveness. As a result, a single original idea is not enough to regularly achieve harmful goals; rather, continuous generation is needed. Consequently, an ideational arms race ensues between law enforcement and offenders, with each group attempting to stay a step ahead with original ways to help or hurt society.

Such concepts raise questions regarding the status of creativity as a virtue (Gaut, 2010). There are different stakeholders in the creative endeavor, from the actor to the audience (Glăveanu, 2013) and the judgment of what is creative is subjective. Yet a general consensus tends to emerge among experts about which products are more or less creative (Amabile, 1996; Kaufman \& Baer, 2012). Similarly, the perception of what constitutes an effective act or a desirable outcome is subjective as well (Cropley et al., 2014). For example, composing music or designing scientific experiments are typically considered to be beneficial, or at least not harmful. Yet devising a new way to embezzle funds, creating an improvised explosive device (IED), or becoming the leader of a murderous cult are detrimental to all those impacted. However, they are still likely to be useful to their creators.

Cropley (2010; Cropley \& Cropley, 2013) connected the interplay of individuals engaging in malevolent creativity, the formulation of destructive ideas, the actions themselves, and the contexts within which they developed to Rhodes' (1961) classic Four Ps model (person, process, product, and press). The person's intended valence applied across 
press/process (supportive or obstructive) would result in a product characterized as good or bad depending on what occurred between the intent and its realization. Cropley (2010) thus proposed eight types of creativity through a $2 \times 2 \times 2$ interaction. Prototypical malevolent creativity would be conscious malevolence (a person with malevolent intent yielding a bad product). Ideal benevolent creativity would arise from a person with benevolent intent creating a good product. However, this one-to-one correspondence between intentions and outcomes is not necessary; individuals could display failed or frustrated creativities. The former includes intents (bad) that correspond with supportive elements but lead to the opposite outcome (good), such as an innovative heist where robbers accidentally trip the alarm, resulting in the bank improving their internal security protocol. The latter occurs when the intention is to harm, but its realization is obstructed, resulting in a good outcome. In this case, the heist may be thwarted by guards who successfully stop the perpetrators. Resilient malevolence (and benevolence) takes place when despite hindrances, the nature of the intent yields a corresponding outcome; for instance, despite the alarm going off, the heist is successful.

Assessing malevolent creativity through this preliminary framework helped examine changes in valence across the Ps and their resulting effects on the eventual output. It elucidated how positive/benevolent and negative/malevolent can be two sides of the same creative coin, which when flipped can land on either side. However, when the coin is weighted by the individual's characteristics, sociocultural contexts, and cognitive and motivational drives, it is more likely to fall one way over the other. ${ }^{i}$

Owing to increased interest and scholarship in the dark side of creativity, we believe the time is apt to propose a framework that explains its development and manifestation. Drawing from existing theories in creativity, evil, and morality, we present an interdisciplinary account of how and why undesirable forms of creativity materialize. An 
important caveat of the model is that it only applies to conscious, intentional acts of creativity, and not unintended and unforeseen consequences. The subsequent sections outline the model sequentially by referring to Figure 1. As we go through the model, gaps in our empirical understanding of the theory will be highlighted, thereby providing insights for future research.

\section{An Overview of the AMORAL Model}

The AMORAL model encompasses the Antecedents, Mechanisms (individual), Operants (environmental), Realization, Aftereffects, and Legacy of dark creativity. These sub-components comprise a combination of top-down influences from stage-based and componential models (Amabile \& Pratt, 2016; Glăveanu, 2013; Mumford et al., 1991; Rhodes, 1961; Sternberg \& Karami, 2021) and bottom-up applications of dark creativity. The AMORAL components represent a convergence of deductive and inductive reasoning, as this is the first theoretical framework to elucidate the emergence of dark creative actions and their repercussions.

First, antecedents are the drivers of dark creativity, including the need to wield power, acquire resources, fulfil hedonistic desires, and align actions with belief systems. These motivators are proposed to interact with individual mechanisms and environmental operants of creative expression. The former includes a general propensity to be creative, intellectual ability, action-relevant knowledge, personality, socio-emotional skills, and personal values; the latter includes broader environmental factors like material and social assets, and cultural ideology. Antecedents, mechanisms, and operants interact with each other in a bi-directional manner; this interaction leads to the realization of the creative action, which is proposed to be moderated by five factors. 
The first is the intended valence of the act, where we propose a grading scale from noble to neutral to ambiguous to self-interested to sinful to evil. We also theorize that certain sub-mechanisms facilitate the movement of valence from neutral to evil, namely deception, manipulation, and coercion. Other factors include the nature of the actor (number of people involved and potential interrelationships), the nature of target (in particular its proximity), the domain, and an element of chance.

The realization of the action leads to immediate and/or short-term aftereffects that can vary on the basis of the breadth, depth, and actual valence of the deed. This gap allows a lack of a one-to-one correspondence between intended and actual valence. Last, the legacy of the dark creative behavior is proposed to have longer-term consequences. These can represent changes in rules and regulations to prevent future detrimental actions or in the establishment of historical significance for the actor and action. Throughout this article, the AMORAL model is illustrated using real-world and hypothetical examples of dark creativity across domains.

\section{Antecedents}

What drives people toward creative misbehaviors? In line with motivational theories, we argue that there are both extrinsic and intrinsic factors (Amabile, 1997), but also include influences like vices and overarching belief systems that are more pertinent to dark creativity. Some motivators like power or accumulating wealth are relevant to creativity in general. However, we will highlight examples relevant to dark creativity.

\section{Power}

This antecedent encompasses the needs for individual achievement and power (McClelland, 1961), possibly at the cost of affiliation motives. It emphasizes upward and forward motion in stature. From stepping on people's toes to bulldozing the competition, the ultimate goal of advancement is either selfish (at others' expense) or self-serving. An 
example might be the treasurer of a local organization who longs to be president. Perhaps they concoct a negative rumor about the current leadership to get the president to resign so they can take over. This concept aligns with research suggesting that under conditions of unstable power, persons in low power positions tend to be more creative than those with higher power, particularly when power can be gained through creativity (Sligte et al., 2011). Further, perceived social threats have been shown to increase malevolent creativity (Baas et al., 2019). Taken together, it is reminiscent of the comedic mantra to always "punch up" - to make fun of those with more cultural power than you have, not less (Prussack, 2018). Perhaps dark creativity is motivated in a similar manner: by creative underdogs seeking to destabilize existing power hierarchies.

\section{Resources}

Accumulating money or other tangible resources through novel actions is another possible antecedent for creativity. Earlier research suggested that such extrinsic motivators could undermine creativity (e.g., Amabile, 1993). Subsequent work pushed back and noted the potential beneficial use of rewards such as the promise of praise (Byron \& Khazanchi, 2012); certainly, rewards can work in synergy with intrinsic drivers, such as the joy of creation, yielding novel outcomes (Hennessey, 2019). In the context of dark creativity, examples of embezzlement or fraud abound, as do instances of milder counterproductive work behaviors, like taking home office stationery. Edith Chase siphoned off funds from her employer and remained undetected for eight years, tricking the company into paying for her loans taken against her pension account through creative bookkeeping (Simmons, 2015). Such instances can occur on a much larger level; consider the Enron scandal, which resulted from corporate corruption and widespread fraud. In both instances, access to money and resources was a primary motivator.

\section{Hedonism}


This driver includes the pursuit of pleasure and self-indulgence that can manifest in behaviors such as vices or immoral recreational activities. Although research on intrinsic motivators of creativity (such as enjoyment or fulfilment) indicates that these are important antecedents (Amabile, 1993; Amabile \& Pillemer, 2012), hedonism is not associated with creative accomplishments (Dollinger et al., 2007). However, research has yet to examine how hedonistic thinking can inspire dark creativity via illicit pleasures like drugs, alcohol, or gambling. Though vices and virtues differ across cultures, we refer to ones considered illegal or unethical in a given setting and which are harmful to others. Finding new ways to smuggle contraband into prisons, as illustrated by the Netflix series Orange is the New Black, shows hedonism guiding creative misbehaviors. Inmates have been known to hide drugs or weapons in such locations as radios, mail, and coffee jars (Singer, 2010). Another proposed antecedent of dark creativity can be the sadistic pleasure derived from causing the physical or emotional suffering of others. This motivator can result in actions ranging from trolling others online (Buckels et al., 2014) to more serious crimes involving sexually sadistic acts (Dietz et al., 1990).

\section{Belief System}

An individual's belief system, or their interconnected set of beliefs (Usó-Doménech \& Nescolarde-Selva, 2016), helps determine whether and to what extent they engage in dark creativity. The conviction that the Aryan race is superior to all others was a systemic belief held by many Nazis that led them to commit unspeakable atrocities. Titlestad (2009) outlines Hitler's creative rhetoric to appeal to all who would listen. Religious fundamentalism magnifies differences between the ingroup and outgroup. Creative actors directed by such beliefs may foster extensive social conflict (Saroglou, 2016). Acts of innovative terrorism fall within the larger purview of beliefs being a chief antecedent for dark creativity, which are opposed by novel actions based on different belief systems (see also Cropley et al., 2008). 
Another instance is conspiracy theories, some of which can be conceptualized as creative narratives that may explain away random events (Bonetto \& Arciszewski, 2021). However, beliefs in conspiracy theories are often harmful, particularly in public health contexts (Salali \& Uysal, 2020).

\section{Mechanisms (Individual)}

Most personal characteristics tend to be shared regardless of the act's valence. However, this model argues for certain individual-level features that may perform the function of an accelerator or handbrake in the context of dark creativity. The antecedents and mechanisms are proposed to share a bidirectional relationship; for example, a person's belief system may shape their ethical values, which can in turn influence beliefs. Similarly, the individual-level mechanisms are interconnected and can influence each other.

\section{Propensity to be Creative}

This component distinguishes our model from others focused exclusively on evil (Calder, 2018). The desire, likelihood, and ability to engage in novel thought and effective behaviors is the most salient mechanism. Without this propensity to be creative, the following individual-level features would be comparable to the characteristics of any evil-doing agents (e.g., Horne, 2008). This component is akin to the creativity-relevant processes outlined by Amabile and Pratt (2016) in their componential theory, such as risk-taking, making unusual associations, and having high creative self-efficacy. Going back to Edith Chase, her engagement in creative (as opposed to ordinary) embezzlement allowed her to continue stealing from her employer for a longer time.

\section{Intellectual Ability}

Research has consistently found that intelligence is a necessary but not sufficient condition for creativity (e.g., Dul et al., 2020). The contribution of intellect as a mechanism has been examined sparsely in studies of dark creativity. Gutworth et al. (2016) found that 
GPA and SAT verbal scores predicted originality but not malevolence in divergent thinking tasks. Yet we argue a certain level of intellect is required to conceive of and successfully implement dark and original ideas. There is a reason why books (Kirchhoff, 2020) and TV series (Cilo, 2008) focusing on the "World's Dumbest Criminals" are considered comedies.

\section{Action-Relevant Knowledge}

This mechanism is similar to domain-relevant knowledge and skills referred to in earlier literature and creativity theories (Amabile \& Pratt, 2016). Just as domain-relevant knowledge and skills can encompass writing in iambic pentameter or calculating a scale's reliability, action-relevant knowledge for dark creativity may include knowing how to hack into a database or manipulate someone's emotions. Thus, comparable to benevolent creativity, those within darker domains are also proposed to differ on action-relevant knowledge and expertise (e.g., Gill et al., 2013).

The importance of action-relevant knowledge is exemplified in the television series Breaking Bad, in which Walter White is a chemistry teacher-turned-drug dealer. He is in charge of producing crystal meth (at least at the start), whereas his partner Jesse Pinkman's forte is bootstrapping a low-cost distribution network for selling the product. Without giving away too many spoilers, the two characters use ingenuity and expertise in their respective domains to avoid capture.

\section{Personality}

Personality has been examined in relation to dark creativity more than any other mechanism. Research has suggested associations between malevolent creativity and trait physical aggression (Lee \& Dow, 2011), implicit aggression, low preparation/forethought (Harris \& Reiter-Palmon, 2015), and anger (Cheng et al., 2021; Perchtold-Stefan et al., 2020a). One area of focus is the Dark Triad traits of psychopathy, narcissism, and Machiavellianism. Studies have found associations between negative/harm-based creativity 
and Machiavellianism (Jonason et al., 2017) and psychopathy (Kapoor, 2015), specifically secondary psychopathy (Kapoor \& Khan, 2018a).

Another undesirable characteristic associated with negative creativity is deception (Kapoor \& Khan, 2017); individuals who think of self-interested creative ways to meet their goals often tend to be dishonest. Of the Big Five traits, one study found a positive association between the trait of openness/imagination with negative creative ideas (Kapoor \& Khan, 2018a). On the other hand, both higher (Gutworth et al., 2016) and lower levels of conscientiousness (Kapoor \& Khan, 2018a) have been associated with dark creativity, pinpointing the need for further investigation. ${ }^{\text {ii }}$ Other personality constructs that merit exploration in this context are the honesty-humility trait from the HEXACO model, Gray's Behavioral Inhibition/Activation Systems, and sadism, which is recently added to the Dark Triad to form a Dark Tetrad.

\section{Socio-Emotional Skills}

This individual-centric feature refers to several social and emotional abilities, including identifying and managing emotions, navigating social situations based on emotional assessment, knowledge of social norms, and using emotions to facilitate reasoning (Mayer et al., 2008). Past work has suggested socio-emotional intelligence has its own dark side, in that aspects can be used to manipulate others. Those high on the Dark Triad, particularly Machiavellianism, are likely to use such an interpersonal strategy to meet their needs (e.g., Nagler et al., 2014). Conversely, higher malevolent creativity has been associated with lower emotional intelligence (Harris et al., 2013), again highlighting the need for more research.

Dark creativity is also likely to share inconsistent relationships with moral emotions. These include guilt, experienced when individuals violate moral norms (often in relationships) and shame, a result of transgressions in hierarchical settings (Haidt, 2003; 
Tangney et al., 2007). Therefore, the capacity to experience guilt and shame can dissuade creative individuals from more destructive outlets. Similarly, if an individual is less likely to experience negative aesthetic emotions, like anger and disgust (Silvia, 2009), they may not be averse to creating provocative works of art.

\section{Personal Values}

Schwartz (2003) proposed a series of ten core values. Some are related to antecedents already discussed (such as power, hedonism, and achievement). Some are positively linked to creativity, such as stimulation and self-direction, whereas others tend to be negatively associated (such as tradition, security, and conformity; see Dollinger et al., 2007). The final two values, benevolence and universalism, would seem to be more related to positive creativity than dark creativity. Given that there is evidence that values are not simply differentially related to creativity but also show distinct patterns based on creative domains (Lebedeva et al., 2019; Taylor \& Kaufman, 2020), the specific value structures associated with dark creativity would be interesting for future exploration.

Other research has found that justifying unethical decisions was easier for creative individuals in ambiguous ethical situations (Gutworth \& Hunter, 2016) and when primed to be creative (Mai et al., 2015), perhaps owing to cognitive and moral flexibilities. Similarly, research has begun examining the links between creativity, morality, and unethicality (Shen et al., 2019; Storme et al., 2020), with inconclusive findings. A useful framework to study the intersection of dark creativity and morality is the Moral Foundations Theory (MFT; Graham et al., 2013). MFT proposes that five universal pillars guide ethical behavior. Harm/care is the extent to which concern towards others is exhibited; Fairness/reciprocity aligns with beliefs about justice and equal treatment; Ingroup/loyalty is the extent one cooperates with the ingroup; Authority/respect includes adherence to hierarchical authority; and Purity/sanctity includes feelings of disgust toward impure transgressions. Care and fairness 
are individualizing foundations associated with individual-level concerns, whereas ingroup, authority, and purity are binding foundations associated with greater concern for the group's values (Graham et al., 2009).

In line with MFT, the earliest empirical work on dark creativity (Clark \& James, 1999) assessed whether being treated unfairly would increase negative creative behaviorsand it did, to an extent. Further, Kapoor and Kaufman (2021) investigated which moral foundations were reliably predictive of creativity and malevolent creativity, particularly against the background of dark personality traits. Whereas malevolent creativity was associated with lower concerns for all moral foundations, creativity was explained by higher individualizing, but lower binding foundations. The intersection with personality was also noteworthy: individuals with less moral concern were more likely to engage in original harm, especially when high on Dark Tetrad traits. Therefore, MFT is a prime area of study given these preliminary findings as well as the salience of moral foundations as personal values. For instance, those who enjoy dark humor will likely have different values than those who prefer cleaner jokes (Kapoor \& Karandikar, 2019).

Theoretically, dark creative actions are also related to moral decision-making, in that planning to start a malicious rumor about a colleague or intentionally committing identity fraud are value-driven choices. Understanding the moral context and consequences of one's creative actions in such contexts can yield utilitarian moral judgements. For instance, would the actor's behavior be justified if the colleague cheated on the actor's partner? Creative solutions to such moral dilemmas can provide further insights into dark creativity and its moral underpinnings.

\section{Operants (Environmental)}

Situating all original acts, regardless of valence, within a larger context is paramount to a holistic understanding of creativity (e.g., Glăveanu, 2015). Environmental operants relate 
to the amplifiers, modifiers, and attenuators of dark creativity. They may explain how and why individuals choose such a route to achieve their objectives. The overall milieu includes the ability to find and utilize resources for creative misbehavior, then expands from the immediate network to broader sociocultural ideologies. As with individual mechanisms, environmental operants are theorized to share a bidirectional relationship with antecedents.

\section{Material Assets}

Glăveanu's (2013) bifurcation of creative press into affordances and audiences suggests the first two operants, material and social assets. Creativity tasks involving broader contexts, such as real-world divergent thinking problems, facilitate more negatively original ideas compared to more decontextualized tasks like the Alternate Uses Test (Kapoor \& Khan, 2018b). Being able to access, use, and manipulate supplies in one's surroundings can constrain or expand the nature of creative outcomes. For instance, the invention and sustained use of nail bombs (explosives containing nails to increase harm) and other IEDs only require easy-to-access household components and basic technical know-how. If there is easier access to large-scale weapons (such as assault rifles or C4 bombs), these may be used in lieu of handmade armaments. In such cases, devising an original way of hurting others may simply not be needed.

\section{Social Assets}

Just as creators can use material goods to attain their goals, they can also leverage social circles, from mentors to audiences to peers. For instance, both formal, explicit goals and informal situational cues, like having someone suggest a single destructive idea, can promote malevolent creativity (Gutworth et al., 2016). An accessible social resource is one's ingroup, which can include one's family, peer group, neighborhood, country, or more. People innovated within the norms of their ingroup when (a) creating a new product together and (b) the group's shared social identity is made salient (Adarves-Yorno et al., 2007). Therefore, 
this operant ranges in its influence from the nature of actors involved to commonly held beliefs by a group. Consider a cocaine dealer. Their social operants may include their suppliers, clients, local police to be evaded, and even politicians and policy-makers who determine the drug's legality and punishment for smuggling. We further theorize that in the case of extreme indoctrination, such as terrorist gangs, ingroup influences can directly lead to targeting outgroup members using novel methods to maximize damage.

In a similar vein, when individuals rationalize instances of deliberate or instructed harm toward others, they may tend to morally disengage from their actions and victims (Bandura, 2016). Such actors may convince themselves that specific ethical standards do not apply to them, as an extreme case of moral relativism. Further, individuals who tend to morally disengage prior to an unethical act may also experience negative emotions like guilt and shame upon learning of the act's consequences (Tillman et al., 2018). However, the mediation of moral emotions between moral disengagement and dark creative behavior remains to be examined. Importantly, as moral disengagement tends to emphasize otherizing, it may also be crucial to situate this within MFT, particularly the ingroup foundation.

\section{Cultural Ideology}

In the AMORAL model, we define cultural ideologies as overarching backdrops against which dark creativity may emerge (Griffin, 2006). The ever-changing nature of ideologies emphasizes how different actions may evolve in perceptions of originality and harmfulness. The one-time practice of sati, in which Hindu widows self-immolated atop their husband's funeral pyre, was a dramatic custom meant to preserve the "honor" of widows by literally extinguishing them. In retrospect, sati was a cruel, misogynistic, yet ingenious cultural practice that stripped women of their rights under the garb of tradition (Mani, 1987). One explanation for the Salem witch trials also links ideology with more practical causes, suggesting that underlying the accusations of witchcraft were long-abating land and political 
disputes (Boyer \& Nissenbaum, 1993). Weaponizing sociocultural values in innovative ways by using misinformation is an instance of dark creativity, relevant in modern times of partisan political ideologies (e.g., Pennycook \& Rand, 2019).

\section{Realization}

The interaction of the antecedents, individual mechanisms, and environmental operants culminates into the realization of the dark creative action. Numerous facets characterize this action, including its intended valence, the natures of the actor and target, and the context in which the behavior occurs. These facets work alongside situational considerations such as luck and random occurrences.

\section{Valence (Intended)}

We distinguish between the intended valence of the action and its actual valence, accounting for possible incongruence between intention and outcome, akin to Cropley's (2010) model. Further, we propose that valence is better represented by a continuum, ranging from noble to neutral to ambiguous to self-interested to sinful to evil. Noble serves as the benevolent anchor for the scale, representing most typical creative actions (even if the positive valence is as slight as mild amusement). Neutral includes creative actions without a clearly discernible valence; an example could be mind-wandering that does not lead to a specific outcome. Although we acknowledge that nearly all acts, particularly creative acts, likely have a tinge of positive or negativity, neutrality is included in discussions of valence (Gasper et al., 2019).

Settings with an ambiguous valence are likely to be ethically complicated, without a clear right or wrong (Cropley et al., 2014); an example is Marvel supervillain Thanos' decision to eliminate half the living beings in the universe to prevent overpopulation. Selfinterested aligns with the definitions of negative creativity; the action serves oneself first without concern for others. Any harm is an unintended byproduct (although not considered a 
priority to avoid). Sinful includes actions targeting an intentionally bad outcome. If the purposeful and original harm is particularly malevolent, it would become the other anchor of the scale, evil.

Consider different kinds of theft that can illustrate progressively darker valence. At the ambiguous level is a theft that is ethically defensible, such as Jean Valjean stealing a loaf of bread to feed his sister's family in Les Misérables. Going back to Edith Chase, her acts of embezzlement fit the self-interested category. Next, Frank Abagnale, the subject of Catch Me If You Can, would impersonate different professions to con substantial sums of money. His persistent deception, despite being pursued by law enforcement, goes beyond self-interested and into sinful. The final stage of evil is when the harm is as desirable as any potential gain. Imagine a criminal who chooses to rob a target specifically because they know that the victim is saving for a child's cancer treatments.

Sub-mechanisms. In order to move across the grayscale of creative actions, we propose sub-mechanisms that assist this progression. Deception, manipulation, and coercion can modify the magnitude at which dark creativity is realized, thereby interacting with the factors constituting the action. Deception and dishonesty have been associated with creativity (Beaussart et al., 2013) and specifically negative creativity (Kapoor \& Khan, 2017). Such manipulation may incorporate aspects of emotional intelligence traditionally considered benevolent, such as understanding other people's emotions and regulating one's own (Mayer et al., 2008). The ADCAT (Activation-Decision-Construction-Action Theory) specifies cognitive and emotional resources required to deceive in situations where the truth is sought (Walczyk et al., 2014). The four components include (a) activating the truth in long-term memory, (b) deciding whether and how to deceive, (c) constructing a lie that will be high in deceptiveness, and (d) communicating the lie. However, there may also be a trade-off between plausibility of a deception and its inventiveness (Walczyk et al., 2014). 
Manipulation differs from deception in that it need not rely on dishonesty (Cohen, 2018); it can include gaslighting, relational aggression, and emotional blackmail (Noggle, 2018). Psychological or physical coercion is the use of threatened or actual force to make targets behave in ways the actor wants. Coercion is frequently used in describing fictional dystopian regimes such as in 1984 and The Handmaid's Tale, which depict novel ways of extracting compliance. More broadly, coercive behaviors also include physical aggression (Anderson, 2017). Further, we posit that any of these sub-mechanisms can help expand the network of actors and thereby increase the radius of harm caused to potential targets.

\section{Nature of the Actor}

The actor in dark creativity is not only the entity who conceives of the deviant act, but also any accomplices. Therefore, the nature of the actor refers to the number of people involved, whether one person, a pair, a small group, or a larger network of actors. As the total number of actors increases, relationship complexity grows. Whereas a pair of actors may have a more egalitarian relationship, a larger quorum of conspirators may form a hierarchical system.

To illustrate the nature of actors in this model, consider Ted Bundy. This organized and calculating serial killer often lured women by pretending to have his arm in a sling and requesting help in carrying something into his vehicle (a technique later used by characters in Silence of the Lambs and The Vanishing). The toolbox killers_-Lawrence Bittaker and Roy Norris - are an example of a pair of equally malevolent actors; their originality lay in the methods used to torture victims using common tools. A duo with a more uneven power balance is the Joker and Harley Quinn from the DC comics universe. The Joker consistently manipulates Quinn, often incriminating her (Salter, 2020). Yet Quinn is also capable of independent ingenious harm, such as using exploding video games to kill children (Flavell, 2020). 
Within small groups, the Manson Family is an illustrative case of dark creativity. Led by Charles Manson, the family members were responsible for sensational murders (Atchison \& Heide, 2011). Manson himself did not commit a single (known) act of physical violence. Instead, he coerced his followers to commit crimes instead. Finally, an actor who leads a large network is likely to be charismatic and sinister. The Third Reich, led by Hitler, instituted a wide array of malevolent and dehumanizing actions to systematically destroy millions of Jewish people and other groups (Kershaw, 2004).

\section{Nature of the Target}

Dark creativity often requires a target toward whom the malevolence is directed (Kapoor \& Khan, 2018b). The target is theorized to have two components: proximity and focus. Proximity is the gap between an original thought and its behavioral counterpart, a corresponding action. Focus is the extent of people, including social structures and systems, that are in harm's way.

Proximity. This component is suggested to fall along a continuum of changing degrees of interactions with others:

(a) Pure fantasy involves no action and is only related to negative ideation and daydreaming. Thinking of terrible novel things that you could do to your boss would fall within this category; there is no behavioral component.

(b) Single-user virtual reality (VR) is an immersive or non-immersive (screenbased) form of VR, such as computer games with an interactive, virtual environment. Within this category are dark creative behaviors undertaken within a pretend setting that do not inflict damage in real life. We include video games that facilitate creative destruction (Cropley, 2015) and cheating (Hamlen \& Blumberg, 2015) with no real-world impact. 
(c) Discussion only involves talking about the potential behavior. Past research on dark creativity that uses real-world problems to examine how individuals might engage in harm-based originality can be classified here (e.g., Gutworth et al., 2016; Harris \& Reiter-Palmon, 2015). On an everyday level, it might include two friends having a hypothetical discussion about pulling off the perfect crime.

(d) Multi-user VR differs from single-user VR in that multiple users appearing as avatars can interact in a virtual space (Brey, 2009). Therefore, destructive originality can be directed toward the avatars of real people in this virtual environment who can experience harm in reality, as a function of such acts. An instance of cyberrape was first discussed by Dibbell (1993); such virtual assaults may lead to real-life traumatic consequences (e.g., Sander, 2009). Less destructively, a veteran video game player in an online game might target new players to plunder their in-game resources (potentially bought with real money).

(e) Physically distant reality involves actions carried out in the real world, but at a substantial distance from the target. The innovative use of hacking to cause harm is included within this category (e.g., The Impact Team; Kapoor et al., 2016). A less severe example includes using a model simulation, such as destroying effigies of disliked persons, to express dissent. Creatively hurtful behaviors on social media such as trolling (Buckels et al., 2014) or deliberately spreading misinformation or conspiracies that lead to real-world harm are other examples (Bonetto \& Arciszewski, 2021).

(f) Physically dissimilar reality entails actions performed by an actor who is physically distant but causes tangible damage to the target. Examples include a drone attack, an innovatively planned contract killing, or the tactic of swatting. 
The latter involves falsely reporting a serious crime or emergency, such as a bomb threat, leading to emergency services redirecting critical resources.

(g) Physically close reality constitutes the most proximate and possibly most destructive form of dark creativity. The examples of innovative terrorism and creative serial killers fall within this category and often involve bodily injury to the target. Most acts of violence would be included here.

Focus. The number of entities targeted by a dark creative action vary on the basis of its focus. We propose that targets can be at the individual, group, national/global, or systemic level. Individual targets are single entities toward whom the behavior is directed; the perpetrators may be multiple actors. In the heist movie Ocean's Eleven, one individual is specifically chosen to be the target by (initially) one person, who then gathers a small group of conspirators. Similarly, individual targets may be spontaneously chosen and are not necessarily predetermined (such as a mugger selecting an opportune victim). At the group level, we would predict that targets would often be members of the outgroup perceived to be dissimilar to the actor. Preventing members of a specific community from renting spaces while avoiding documentable biased behavior would inventively target the outgroup (in line with the discussion on moral disengagement). At the global level, original harm is directed toward citizens of a specific nation or culture. The terrorist attacks of 9/11 in New York City or 26/11 in Mumbai (November $26^{\text {th }}, 2008$ ) would be examples of this larger and wider scale of innovative destruction. Last, targets at the systemic level can be identified through the use of ideology backing their actions. For instance, Alexandra Elbakyan's website Sci-Hub offers free access to paywalled academic content and targets the lopsided business model of academic publishing.

\section{Domain}


This facet is the broad area within which the action is employed-public, private, online, and offline. Initial papers on the dark side of creativity outlined this behavior in artistic, technological, scientific, and organizational domains (McLaren, 1993). Subsequent work has expanded to terrorist and criminal activity (Cropley et al., 2008), video games (Cropley, 2015), educational settings (Kapoor, 2019), dark humor (Kapoor \& Karandikar, 2019; Perchtold-Stefan et al., 2020b), and social media (de Saint Laurent et al., 2020). It is easy to consider other potential additions, such as advertising, propaganda, and interpersonal communication (such as the spread of fake news or misinformation).

\section{Chance}

Although the AMORAL theory should primarily be applied to intentional and deliberate acts of dark creativity, we also recognize that chance or luck plays a role in the realization of the behavior. Particularly relevant is the concept of moral luck, when the actor receives undue praise or blame for events that were beyond their control (Hartman, 2019). Consider, for example, two criminals who both choose to use an IED in a crowded public area. The first criminal's IED explodes and kills dozens of people. The second criminal's device fails due to a technical error and no one is injured. The latter would be morally lucky and assigned less blame. However, the intentions of both criminals were to cause harm, which would make both equally morally responsible. The disparity between the intention and outcome for the second criminal but the congruence of the two for the first criminal leads to this difference in judgment. Sudden opportunities can also influence how the behavior will be realized, assuming the necessary antecedents, mechanisms, and operants are in place. If an individual finds a gap in their company's security protocol, they may be honest and work to resolve it - or they may game the system and monopolize on the discovered loophole.

\section{Aftereffects (Immediate and/or Short-Term)}


The immediate and short-term consequences of dark creativity depend on the scale and extent of its realization. Specific characteristics such as the breadth of harm, depth of harm, and realized valence of the outcome will determine the aftereffects. Of course, this argument only considers those individuals whose misdoings have been discovered. A murder incorrectly considered to be a natural or accidental death may present no aftereffects at all.

\section{Breadth and Depth}

The variation in the breadth (how many targets) and depth (how much harm to targets) influences the extent of the action's aftereffects. To illustrate, consider the examples of two new-age cults and charismatic leaders active in the 1970s and 1980s: the Rajneesh Movement, led by Bhagwan Shree Rajneesh (Osho), and the Peoples Temple Agricultural Project, led by Jim Jones. The former was a commune that began in India, but relocated to Wasco County, Oregon, to establish Rajneeshpuram. Local residents and authorities set up a vote to disincorporate this new community. Aiming to disrupt the election, Osho's secretary Ma Anand Sheela and other leaders deliberately contaminated local salad bars with Salmonella, poisoning over 700 Americans in an act of bio-terrorism. Although several fell ill and were hospitalized, none died. Thus, the breadth and depth of harm caused was restricted.

The Peoples Temple cult, led by Jim Jones, started in the United States in the 1970's before moving to Guyana to avoid growing media attention. There, he established Jonestown. When Jones was on the verge of being uncovered as a charlatan by a group of Americans led by congressman Leo Ryan, he ordered them to be murdered. He then coerced over 900 followers (one-third children), to commit suicide by poison before shooting himself.ii ${ }^{\text {ii }}$ The Jonestown massacre is one of the most elaborate and devastating realizations of dark creativity that still resonates due to the extent and gravity of harm.

\section{Valence (Actual)}


The intended valence of the planned act need not correspond with its eventual realized valence. Going back to moral luck, if conscious malevolence is thwarted and results in a benevolent (or, at least, unharmful) outcome, it will be perceived differently (Cropley, 2010). Conversely, a noble intention may morph into an evil outcome. Consider for example, the drug thalidomide. Initially prescribed for anxiety and sleeplessness in the 1950s, it was soon discovered to mitigate the effects of morning sickness in pregnant women. However, the use of thalidomide led to babies born with severe birth defects, such as shortened or flipper-like limbs. Benevolent but misguided intentions led to unintended consequences of lasting harm.

On the other hand, malevolent acts like widespread human experimentation in Nazi Germany contributed to the development of a benevolent protocol: ethical standards for human subjects' research. Although the intended and actual valence can be congruent or incongruent, aftereffects are nearly always determined by the eventual valence of the realized act.

\section{Legacy}

In addition to immediate and short-term repercussions of dark creative acts, we propose that certain realizations and actors can achieve a legacy status over time. This is similar to the Four-C model that suggests a developmental trajectory underlying creative progression. The ultimate Big-C category is reserved for eminent creators who maintain their influence over time (Kaufman \& Beghetto, 2009). We theorize that certain devious and original actors attain a comparably notorious status over time. Their actions can result in long-term consequences, which are not necessarily always negative.

\section{Long-Term}

What makes certain serial killers more memorable than others? Or cult leaders? Or financial fraudsters? It may be that these actors were the first to ever behave in their characteristic ways (originality) or were extremely successful at achieving their goals 
(effectiveness), or both. It is also likely that their actions were popularized by the media at that time (an immediate and short-term aftereffect), but also continue to be currently represented in popular media (a longer-term consequence). The acts and actors involved in Osho, Jim Jones, Ted Bundy, 9/11, and 26/11 have been the subject of documentaries, fictionalized works, and extensive analysis and discussion. Such ongoing coverage spotlights the devastation caused, yet also focuses on how to prevent future similar occurrences. The continued fascination surrounding the $19^{\text {th }}$ century serial killer Jack the Ripper likely inspired the development of criminal profiling as an investigative tool (Ogan \& Alison, 2005). The enduring effects of dark creativity may be clearest with enough temporal distance, when we can identify ways to learn and prevent future occurrences.

An example of differing legacies can be seen in comparing mass murderers from 1966: Richard Speck, Charles Whitman, and Robert Benjamin Smith. Speck murdered eight nurses in July; Whitman shot 15 others from a tower at the University of Texas in August; and Smith murdered 5 females in a salon in November. However, only Speck and Whitman have been portrayed extensively in popular culture. In contrast, Smith has not even merited a Wikipedia entry. Although all three incidents had elements of dark originality in their modus operandi, Smith is considered a copycat killer, following in the footsteps of his heroes, Speck and Whitman (Day, 2016). He also wanted to "make a name" for himself, whereas Speck and Whitman created legacies, unfortunately, on their own accord. The originality of engaging in mass murder perhaps decayed even in this very short period of months, thereby lowering the likelihood of Smith being remembered (e.g., Cropley et al., 2008).

\section{Implications and Conclusion}

The AMORAL model provides a scaffolding for future research in dark creativity. It helps build a research agenda to examine nuances in original production that may have been side-stepped earlier. In general, research in this relatively newer sub-discipline has proceeded 
in the same way as most psychological research does — with college students as participants.

Moreover, most existing studies in negative and malevolent creativity have assessed responses to hypothetical divergent thinking tasks (e.g., Harris \& Reiter-Palmon, 2015; Kapoor \& Khan, 2018b). From a Four-C perspective, mini and little dark creativity have been examined more often than Pro and Big (Kaufman \& Beghetto, 2009). Novice dark creativity can be employed by laypersons, such as when gaslighting past romantic partners, but expert levels are often achieved by lawbreakers. Although past work has shed light on the intersection of creativity and crime (Cropley \& Cropley, 2013), subsequent research can apply historiometric methods (e.g., Simonton, 1990) to understand particularly innovative criminal activity. The AMORAL model can serve as a guide to make inferences regarding past offenses. Such analyses can feed forward into helping law enforcement identify and predict patterns of creative crime.

Apart from gathering empirical data to supplement the model, there exist far-reaching implications for law and security protocols. Policy changes are often reactive, particularly in the cases of dark creativity, and aimed at preventing future harm. For instance, the Transportation Security Administration (TSA) in the US was formed after 9/11. Since the 2001 shoe bomb attempt, all passengers have been required to remove and screen their shoes during security check. This policy implies that enforcement can learn from creative criminals who either have been caught or successfully realized their dark original acts. Yet acknowledging that creative expression has greyer shades can better prepare lawmakers, academics, and even the general public. Applying the AMORAL model in a systemic manner may at least assist in getting at par with how dark creative actors think, if not ahead of them.

Creativity, including its darker shades, flourishes regardless of time, place, or context. During the COVID-19 pandemic, scientific creativity flourished, with global teams working together to develop a vaccine. Creativity at an individual level also emerged when finding 
novel ways to maintain social distancing or staying active at home. At the same time, there were reports of homemade (and dangerous) hand sanitizers and fake thermometers being sold online (which never showed a fever). Further, because educational institutions had shut down, some teachers started using mobile learning apps to assign homework; clever students downvoted these with fake reviews to shut down those apps. We think it is time to recognize that self-interested, sinful, and evil acts of originality exploit good faith through manipulation and deceit. The introduction of the AMORAL model is, thus, intended to highlight the novel garden paths we may be led along. 


\section{References}

Adarves-Yorno, I., Postmes, T., \& Haslam, S. A. (2007). Creative innovation or crazy irrelevance? The contribution of group norms and social identity to creative behavior. Journal of Experimental Social Psychology, 43(3), 410-416. https://doi.org/10.1016/j.jesp.2006.02.013

Amabile, T. M. (1993). The social psychology of creativity. Springer-Verlag.

Amabile, T. M. (1996). Creativity in context. Westview.

Amabile, T. M. (1997). Entrepreneurial creativity through motivational synergy. The Journal of Creative Behavior, 31(1), 18-26. https://doi.org/10.1002/j.2162-6057.1997.tb00778.x

Amabile, T. M., \& Pillemer, J. (2012). Perspectives on the social psychology of creativity. Journal of Creative Behavior, 46(1), 3-15. https://doi.org/10.1002/jocb.001

Amabile, T. M., \& Pratt, M. G. (2016). The dynamic componential model of creativity and innovation in organizations: Making progress, making meaning. Research in Organizational Behavior, 36, 157-183. https://doi.org/10.1016/j.riob.2016.10.001

Anderson, S. (2017). Coercion. In The Stanford Encyclopedia of Philosophy.

Atchison, A. J., \& Heide, K. M. (2011). Charles Manson and the family: The application of sociological theories to multiple murder. International Journal of Offender Therapy and Comparative Criminology, 55(5), 771-798. https://doi.org/10.1177/0306624X10371794

Baas, M., Roskes, M., Koch, S., Cheng, Y., \& De Dreu, C. K. W. (2019). Why social threat motivates malevolent creativity. Personality and Social Psychology Bulletin, 45(11), 1590-1602. https://doi.org/10.1177/0146167219838551

Bandura, A. (2016). Moral disengagement: How people do harm and live with themselves. Worth Publishers.

Barron, F. (1955). The disposition toward originality. Journal of Abnormal and Social Psychology, 51, 478-485. https://doi.org/10.1037/h0048073 
Beaussart, M. L., Andrews, C. J., \& Kaufman, J. C. (2013). Creative liars: The relationship between creativity and integrity. Thinking Skills and Creativity, 9, 129-134. https://doi.org/10.1016/j.tsc.2012.10.003

Bonetto, E., \& Arciszewski, T. (2021). The creativity of conspiracy theories. The Journal of Creative Behavior, 0, jocb.497. https://doi.org/10.1002/jocb.497

Boyer, P., \& Nissenbaum, S. (1993). Salem-Village witchcraft: A documentary record of local conflict in colonial New England. (P. Boyer \& S. Nissenbaum (Eds.)). Northeastern Press.

Brey, P. (2009). Virtual reality and computer simulation. In K. E. Himma \& H. T. Tavani (Eds.), The Handbook of Information and Computer Ethics (Issue May, pp. 361-384). John Wiley \& Sons, Inc. http://doi.wiley.com/10.1002/9780470281819.ch15

Buckels, E. E., Trapnell, P. D., \& Paulhus, D. L. (2014). Trolls just want to have fun. Personality and Individual Differences, 67, 97-102. https://doi.org/10.1016/j.paid.2014.01.016

Byron, K., \& Khazanchi, S. (2012). Rewards and creative performance: A meta-analytic test of theoretically derived hypotheses. Psychological Bulletin, 138(4), 809-830. https://doi.org/10.1037/a0027652

Calder, T. (2018). The concept of evil. In The Stanford Encyclopedia of Philosophy.

Cheng, R., Lu, K., \& Hao, N. (2021). The effect of anger on malevolent creativity and strategies for its emotion regulation. Acta Psychologica Sinica, 53(8), 847. https://doi.org/10.3724/sp.j.1041.2021.00847

Cilo, J. (2008). truTV presents: World's dumbest criminals. Warner Bros. Television Distribution.

Clark, K., \& James, K. (1999). Justice and positive and negative creativity. Creativity Research Journal, 12(4), 311-320. https://doi.org/10.1207/s15326934crj1204_9 
Cohen, S. (2018). Manipulation and deception. Australasian Journal of Philosophy, 96(3), 483-497. https://doi.org/10.1080/00048402.2017.1386692

Cropley, D. H. (2010). Summary - The dark side of creativity: A differentiated model. In D. H. Cropley, A. J. Cropley, J. C. Kaufman, \& M. A. Runco (Eds.), The dark side of creativity (pp. 360-373). Cambridge University Press.

Cropley, D. H. (2015). Video games and malevolent creativity: Does one thing lead to another? In G. P. Green \& J. C. Kaufman (Eds.), Video games and creativity (pp. 6283). Academic Press.

Cropley, D. H., \& Cropley, A. J. (2013). Creativity and crime: A psychological analysis. Cambridge University Press.

Cropley, D. H., \& Cropley, A. J. (2019). Creativity and malevolence: Past, present, and future. In J. C. Kaufman \& R. J. Sternberg (Eds.), The Cambridge Handbook of Creativity (2nd ed., pp. 677-690). Cambridge University Press.

Cropley, D. H., Cropley, A. J., Kaufman, J. C., \& Runco, M. A. (Eds.). (2010). The dark side of creativity. Cambridge University Press.

Cropley, D. H., Kaufman, J. C., \& Cropley, A. J. (2008). Malevolent creativity: A functional model of creativity in terrorism and crime. Creativity Research Journal, 20(2), 105-115. https://doi.org/10.1080/10400410802059424

Cropley, D. H., Kaufman, J. C., White, A. E., \& Chiera, B. A. (2014). Layperson perceptions of malevolent creativity: The good, the bad, and the ambiguous. Psychology of Aesthetics, Creativity, and the Arts, 8(4), 400-412. https://doi.org/10.1037/a0037792 Day, M. (2016). The story of the first copycat mass shooter. Timeline.

de Saint Laurent, C., Glaveanu, V., \& Chaudet, C. (2020). Malevolent creativity and social media: Creating anti-immigration communities on Twitter. Creativity Research Journal, 32(1), 66-80. https://doi.org/10.1080/10400419.2020.1712164 
Dibbell, J. (1993, December 23). A rape in cyberspace. The Village Voice. http://www.juliandibbell.com/texts/bungle_vv.html

Diedrich, J., Benedek, M., Jauk, E., \& Neubauer, A. C. (2015). Are creative ideas novel and useful? Psychology of Aesthetics, Creativity, and the Arts, 9(1), 35-40. https://doi.org/10.1037/a0038688

Dietz, P. E., Hazelwood, R. R., \& Warren, J. (1990). The sexually sadistic criminal and his offenses. Bulletin of the American Academy of Psychiatry \& the Law, 18(2), 163-178. https://doi.org/10.4324/9781315196756

Dollinger, S. J., Burke, P. A., \& Gump, N. W. (2007). Creativity and values. Creativity Research Journal, 19(2-3), 91-103. https://doi.org/10.1080/10400410701395028

Dul, J., Karwowski, M., \& Kaufman, J. C. (2020). Necessary condition analysis in creativity research. In Handbook of research methods on creativity (pp. 351-368). Edward Elgar.

Flavell, L. (2020). The 10 worst things Harley Quinn has ever done. CBR.Com. https://www.cbr.com/harley-quinn-worst-things-ever-done/

Gasper, K., Spencer, L. A., \& Hu, D. (2019). Does neutral affect exist? How challenging three beliefs about neutral affect can advance affective research. Frontiers in Psychology, 10. https://doi.org/10.3389/fpsyg.2019.02476

Gaut, B. (2010). The philosophy of creativity. Philosophy Compass, 12(5), 1034-1046. https://doi.org/10.1111/j.1747-9991.2010.00351.x

Gill, P., Horgan, J., Hunter, S. T., \& Cushenbery, L. D. (2013). Malevolent creativity in terrorist organizations. The Journal of Creative Behavior, 47(2), 125-151. https://doi.org/10.1002/jocb.28

Glăveanu, V. P. (2013). Rewriting the language of creativity: The Five A's framework. Review of General Psychology, 17(1), 69-81. https://doi.org/10.1037/a0029528

Glăveanu, V. P. (2015). Creativity as a sociocultural act. The Journal of Creative Behavior, 
49(3), 165-180. https://doi.org/10.1002/jocb.94

Graham, J., Haidt, J., Koleva, S., Motyl, M., Iyer, R., Wojcik, S. P., \& Ditto, P. H. (2013). Moral foundations theory: The pragmatic validity of moral pluralism. Advances in Experimental Social Psychology, 47, 55-130. https://doi.org/10.1016/B978-0-12407236-7.00002-4

Graham, J., Haidt, J., \& Nosek, B. A. (2009). Liberals and conservatives rely on different sets of moral foundations. Personality Processes and Individual Differences, 96(5), 10291046. https://doi.org/10.1037/a0015141

Griffin, R. (2006). Ideology and culture. Journal of Political Ideologies, 11(1), 77-99. https://doi.org/10.1080/13569310500395974

Gutworth, M. B., Cushenbery, L., \& Hunter, S. T. (2016). Creativity for deliberate harm: Malevolent creativity and social information processing theory. The Journal of Creative Behavior, 0, 1-18. https://doi.org/10.1002/jocb.155

Gutworth, M. B., \& Hunter, S. T. (2016). Ethical saliency: Deterring deviance in creative individuals. Psychology of Aesthetics, Creativity, and the Arts. https://doi.org/10.1037/aca0000093

Haidt, J. (2003). The moral emotions. In R. J. Davidson, K. R. Scherer, \& H. H. Goldsmith (Eds.), Handbook of affective sciences (pp. 852-870). Oxford University Press. https://doi.org/10.1093/mnras/stx1358

Hamlen, K. R., \& Blumberg, F. C. (2015). Problem solving through "cheating” in video games. In G. P. Green \& J. C. Kaufman (Eds.), Video games and creativity (pp. 83-97). Academic Press.

Harris, D. J., \& Reiter-Palmon, R. (2015). Fast and furious: The influence of implicit aggression, premeditation, and provoking situations on malevolent creativity. Psychology of Aesthetics, Creativity, and the Arts, 9(1), 54-64. 
https://doi.org/10.1037/a0038499

Harris, D. J., Reiter-Palmon, R., \& Kaufman, J. C. (2013). The effect of emotional intelligence and task type on malevolent creativity. Psychology of Aesthetics, Creativity, and the Arts, 7(3), 237-244. https://doi.org/10.1037/a0032139

Hartman, R. J. (2019). Moral luck and the unfairness of morality. Philosophical Studies, 176(12), 3179-3197. https://doi.org/10.1007/s11098-018-1169-5

Hennessey, B. A. (2019). Motivation and creativity. In J. C. Kaufman \& R. J. Sternberg (Eds.), Cambridge Handbook of Creativity (2nd ed., pp. 374-395). Cambridge University Press.

Horne, M. (2008). Evil acts not evil people: Their characteristics and contexts. Journal of Analytical Psychology, 53(5), 669-690. https://doi.org/10.1111/j.14685922.2008.00759.x

James, K., Clark, K., \& Cropanzano, R. (1999). Positive and negative creativity in groups, institutions, and organizations: A model and theoretical extension. Creativity Research Journal, 12(3), 211-226. https://doi.org/10.1207/s15326934crj1203

Jonason, P. K., Abboud, R., Tomé, J., Dummett, M., \& Hazer, A. (2017). The Dark Triad traits and individual differences in self-reported and other-rated creativity. Personality and Individual Differences, 117, 150-154. https://doi.org/10.1016/j.paid.2017.06.005

Kapoor, H. (2015). The creative side of the Dark Triad. Creativity Research Journal, 27(1), 58-67. https://doi.org/10.1080/10400419.2014.961775

Kapoor, H. (2019). Creative resistance in learning environments. In M. A. Peters \& R. Heraud (Eds.), Springer Encyclopedia of Educational Innovation. Springer Singapore. https://doi.org/10.1007/978-981-13-2262-4

Kapoor, H., \& Karandikar, S. (2019). Darkness all around: Humor, personality, and creativity. In-Mind Magazine. https://www.in-mind.org/blog/post/darkness-all-around- 
humor-personality-and-creativity

Kapoor, H., \& Kaufman, J. C. (2021). Unbound: The relationship between creativity, moral foundations, and dark personality. The Journal of Creative Behavior.

Kapoor, H., \& Khan, A. (2017). Deceptively yours: Valence-based creativity and deception. Thinking Skills and Creativity, 23, 199-206. https://doi.org/10.1016/j.tsc.2016.12.006

Kapoor, H., \& Khan, A. (2018a). Creators and presses: The person-situation interaction in negative creativity. The Journal of Creative Behavior, 54(1), 75-89.

https://doi.org/10.1002/jocb.346

Kapoor, H., \& Khan, A. (2018b). Creativity in context: Presses and task effects in negative creativity. Psychology of Aesthetics, Creativity, and the Arts. https://doi.org/10.1037/aca0000183

Kapoor, H., Tagat, A., \& Cropley, D. H. (2016). Fifty shades of creativity: Case studies of malevolent creativity in art, science, and technology. In F. K. Reisman (Ed.), Creativity in Arts, Science, and Technology (pp. 25-44).

Kaufman, J. C., \& Baer, J. (2012). Beyond new and appropriate: Who decides what is creative? Creativity Research Journal, 24(1), 83-91. https://doi.org/10.1080/10400419.2012.649237

Kaufman, J. C., \& Beghetto, R. A. (2009). Beyond big and little: The four c model of creativity. Review of General Psychology, 13(1), 1-12. https://doi.org/10.1037/a0013688

Kershaw, I. (2004). Hitler and the uniqueness of Nazism. Journal of Contemporary History, 39(2), 239-254. https://doi.org/10.1177/0022009404042130

Kirchhoff, J. (2020). The world's dumbest criminals. Harper Collins Publishers Canada. Lebedeva, N., Schwartz, S. H., Van De Vijver, F. J. R., Plucker, J., \& Bushina, E. (2019). Domains of everyday creativity and personal values. Frontiers in Psychology, 9, 1-16. 
https://doi.org/10.3389/fpsyg.2018.02681

Lee, S. A., \& Dow, G. T. (2011). Malevolent creativity: Does personality influence malicious divergent thinking? Creativity Research Journal, 23(2), 73-82. https://doi.org/10.1080/10400419.2011.571179

Mai, K. M., Ellis, A. P. J., \& Welsh, D. T. (2015). The gray side of creativity: Exploring the role of activation in the link between creative personality and unethical behavior. Journal of Experimental Social Psychology, 60, 76-85. https://doi.org/10.1016/j.jesp.2015.05.004

Mani, L. (1987). Contentious traditions: The debate on sati in colonial India. Cultural Critique, 7, 119-156. https://www.jstor.org/stable/1354153

Mayer, J. D., Caruso, D. R., \& Salovey, P. (1999). Emotional intelligence meets traditional standards for an intelligence. Intelligence, 27(4), 267-298. https://doi.org/10.1016/S0160-2896(99)00016-1

Mayer, J. D., Roberts, R. D., \& Barsade, S. G. (2008). Human abilities: Emotional intelligence. Annual Review of Psychology, 59(1), 507-536. https://doi.org/10.1146/annurev.psych.59.103006.093646

McClelland, D. C. (1961). The achieving society. The Free Press.

McLaren, R. B. (1993). The dark side of creativity. Creativity Research Journal, 6(1-2), 137-144. https://doi.org/10.1080/10400419309534472

Mumford, M. D., Mobley, M. I., Reiter-Palmon, R., Uhlman, C. E., \& Doares, L. M. (1991). Process analytic models of creative capacities. Creativity Research Journal, 4(2), 91122. https://doi.org/10.1080/10400419109534380

Nagler, U. K. J., Reiter, K. J., Furtner, M. R., \& Rauthmann, J. F. (2014). Is there a "dark intelligence"? Emotional intelligence is used by dark personalities to emotionally manipulate others. Personality and Individual Differences, 65, 47-52. 
https://doi.org/10.1016/j.paid.2014.01.025

Noggle, R. (2018). The ethics of manipulation. In The Stanford Encyclopedia of Philosophy.

Ogan, J., \& Alison, L. (2005). Jack the Ripper and the Whitechapel murders: A very Victorian critical incident. In L. Alison (Ed.), The forensic psychologist's casebook: Psychological profiling and criminal investigation (pp. 23-46). Willan Publishing.

Pennycook, G., \& Rand, D. G. (2019). Fighting misinformation on social media using crowdsourced judgments of news source quality. Proceedings of the National Academy of Sciences of the United States of America, 116(7), 2521-2526. https://doi.org/10.1073/pnas.1806781116

Perchtold-Stefan, C. M., Fink, A., Rominger, C., \& Papousek, I. (2020a). Creative, antagonistic, and angry? Exploring the roots of malevolent creativity with a real-world idea generation task. Journal of Creative Behavior. https://doi.org/10.1002/jocb.484

Perchtold-Stefan, C. M., Fink, A., Rominger, C., \& Papousek, I. (2020b). Motivational factors in the typical display of humor and creative potential: The case of malevolent creativity. Frontiers in Psychology, 11. https://doi.org/10.3389/fpsyg.2020.01213

Plucker, J. A., Beghetto, R. A., \& Dow, G. T. (2004). Why isn't creativity more important to educational psychologists? Potentials, pitfalls, and future directions in creativity research. Educational Psychologist, 39(2), 83-96. https://doi.org/10.1207/s15326985ep3902_1

Prussack, M. (2018). Punching down: Navigating jokes at someone else's expense.

Glaad.Org. https://www.glaad.org/blog/punching-down-navigating-jokes-someonesexpense

Rhodes, M. (1961). An analysis of creativity. The Phi Delta Kappan, 42(7), 305-310. http://www.jstor.org/stable/20342603

Salali, G. D., \& Uysal, M. S. (2020). COVID-19 vaccine hesitancy is associated with beliefs 
on the origin of the novel coronavirus in the UK and Turkey. Psychological Medicine, 56-58. https://doi.org/10.1017/S0033291720004067

Salter, A. (2020). \#RelationshipGoals? Suicide Squad and fandom's love of "problematic" men. Television \& New Media, 21(2), 135-150.

https://doi.org/10.1177/1527476419879916

Sander, M. M. F. (2009). Questions about accountability and illegality of virtual rape [Iowa State University]. http://search.proquest.com/docview/304907840?accountid=7408

Saroglou, V. (2016). Intergroup conflict, religious fundamentalism, and culture. Journal of Cross-Cultural Psychology, 47(1), 33-41. https://doi.org/10.1177/0022022115621174

Sawyer, R. K. (2012). Explaining creativity: The science of human innovation. Oxford University Press. https://doi.org/10.1016/0140-1750(88)90050-4

Schwartz, S. H. (2003). A proposal for measuring value orientations across nations. Questionnaire Package of the European Social Survey, 259-319.

Shen, W., Yuan, Y., Yi, B., Liu, C., \& Zhan, H. (2019). A theoretical and critical examination on the relationship between creativity and morality. Current Psychology, 38, 469-485. https://doi.org/10.1007/s12144-017-9613-9

Silvia, P. J. (2009). Looking past pleasure: Anger, confusion, disgust, pride, surprise, and other unusual aesthetic emotions. Psychology of Aesthetics, Creativity, and the Arts, 3(1), 48-51. https://doi.org/10.1037/a0014632

Silvia, P. J., \& Brown, E. M. (2007). Anger, disgust, and the negative aesthetic emotions: Expanding an appraisal model of aesthetic experience. Psychology of Aesthetics, Creativity, and the Arts, 1(2), 100-106. https://doi.org/10.1037/1931-3896.1.2.100

Simmons, A. (2015). Creative embezzlement. Fraud Magazine. https://www.fraudmagazine.com/article.aspx?id=4294991086

Simonton, D. K. (1990). Psychology, science, and history: An introduction to historiometry. 
Yale University Press.

Simonton, D. K. (2016). Defining creativity: Don't we also need to define what is not creative? The Journal of Creative Behavior, 1-15. https://doi.org/10.1002/jocb.137

Singer, J. K. (2010). Creativity in confinement. In D. H. Cropley, A. J. Cropley, J. C. Kaufman, \& M. A. Runco (Eds.), The dark side of creativity (pp. 177-203). Cambridge University Press.

Sligte, D. J., de Dreu, C. K. W., \& Nijstad, B. A. (2011). Power, stability of power, and creativity. Journal of Experimental Social Psychology, 47(5), 891-897. https://doi.org/10.1016/j.jesp.2011.03.009

Stein, M. I. (1953). Creativity and culture. The Journal of Psychology: Interdisciplinary and Applied, 36(2), 311-322. https://doi.org/10.1080/00223980.1953.9712897

Sternberg, R. J., \& Karami, S. (2021). An 8P theoretical framework for understanding creativity and theories of creativity. Journal of Creative Behavior, 0, 1-24. https://doi.org/10.1002/jocb.516

Sternberg, R. J., \& Lubart, T. I. (1992). Buy low and sell high: An investment approach to creativity. Current Directions in Psychological Science, 1(1), 1-5.

Storme, M., Celik, P., \& Myszkowski, N. (2020). Creativity and unethicality: A systematic review and meta-analysis. Psychology of Aesthetics, Creativity, and the Arts. https://doi.org/10.1037/aca0000332

Tangney, J. P., Stuewig, J., \& Mashek, D. J. (2007). Moral emotions and moral behavior. Annual Review of Psychology, 58(1), 345-372. https://doi.org/10.1146/annurev.psych.56.091103.070145

Taylor, C. L., \& Kaufman, J. C. (2020). Values across creative domains. The Journal of Creative Behavior. https://doi.org/10.1002/jocb.470

Tillman, C. J., Gonzalez, K., Whitman, M. V., Crawford, W. S., \& Hood, A. C. (2018). A 
multi-functional view of moral disengagement: Exploring the effects of learning the consequences. Frontiers in Psychology, 8(JAN), 1-14.

https://doi.org/10.3389/fpsyg.2017.02286

Titlestad, P. J. H. (2009). Creative rhetoric: Milton's Satan, Adolf Hitler and others. English Academy Review, 26(2), 60-71. https://doi.org/10.1080/10131750903336098

Usó-Doménech, J. L., \& Nescolarde-Selva, J. (2016). What are belief systems? Foundations of Science, 21(1), 147-152. https://doi.org/10.1007/s10699-015-9409-z

Walczyk, J. J., Harris, L. L., Duck, T. K., \& Mulay, D. (2014). A social-cognitive framework for understanding serious lies: Activation-decision-construction-action theory. New Ideas in Psychology, 34, 22-36.

https://doi.org/10.1016/J.NEWIDEAPSYCH.2014.03.001

Wallas, G. (1926). The art of thought. Harcourt, Brace, Jovanovich.

Zontangos, G., \& Anderson, A. . (2009). Understanding entrepreneurial behaviour in organized criminals. Journal of Enterprising Communities: People and Places in the Global Economy, 3(3), 256-268. https://doi.org/10.1177/0266242610391936 


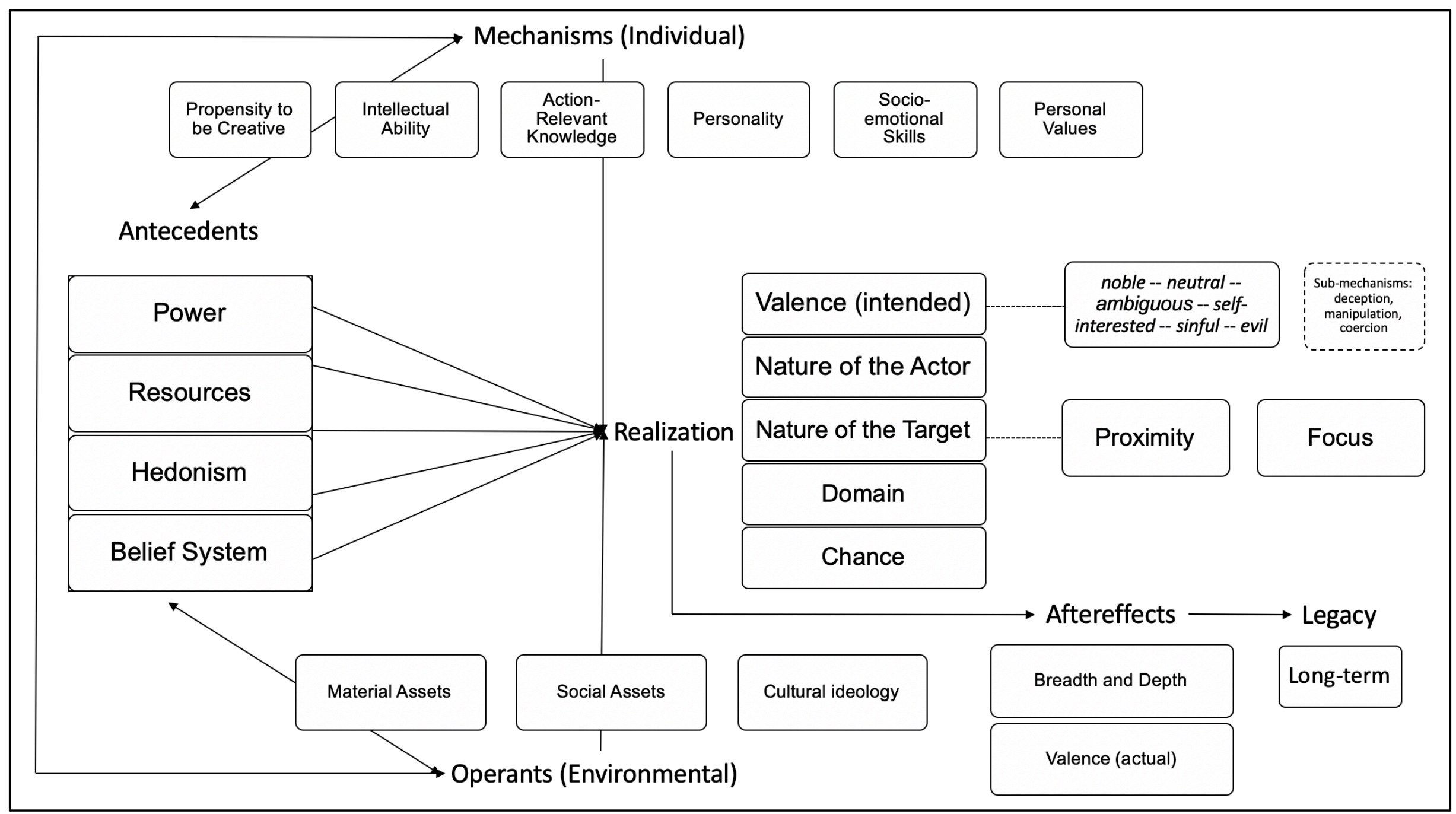

Figure 1. The AMORAL model of dark creativity. 


\footnotetext{
' Cropley and Cropley (2013) differentiated the Person P into three components: personal properties, personal motivation, and personal feelings/mood, proposing 6 Ps of creativity. This revision offered greater nuance to understanding the creative individual, supported by findings such as creative persons being more likely to seek new experiences yet also be dishonest.

ii Although disagreeableness would seem to be relevant to this discussion, research has only found a feeble association with negative creativity (Kapoor \& Khan, 2018a).

iii The documentary Jonestown: The Life and Death of Peoples Temple (2006) by Firelight Media chronicles the events leading up to this mass suicide.
} 